\title{
Observations of the seasonal dietary preference of male Gazella subgutturosa marica Thomas, 1897 (Cetartiodactyla: Bovidae) along foraging trails of central Saudi Arabia
}

\author{
Peter Low Cunningham ${ }^{1,2}$ \\ ${ }^{1}$ King Khalid Wildlife Research Center, Thumamah, P.O. Box 61681, Riyadh, Kingdom of Saudi Arabia \\ 'Zoological Society of London, Conservation Programmes, Regent's Park, London, NW1 4RY, United Kingdom \\ Email: 1,2 pckkwrc@yahoo.co.uk
}

Date of publication (online): 26 September 2009 Date of publication (print): 26 September 2009 ISSN $0974-7907$ (online) | 0974-7893 (print)

Editor: C. Srinivasulu

\section{Manuscript details:}

Ms \# 02154

Received 04 March 2009

Final received 24 May 2009

Finally accepted 29 August 2009

Citation: Cunningham, P.L. (2009). Observations of the seasonal dietary preference of male Gazella subgutturosa marica Thomas, 1897 (Cetartiodactyla: Bovidae) along foraging trails of central Saudi Arabia. Journal of Threatened Taxa 1(9): 445-449.

Copyright: () Peter Low Cunningham 2009. Creative Commons Attribution 3.0 Unported License. JoTT allows unrestricted use of this article in any medium for non-profit purposes, reproduction and distribution by providing adequate credit to the authors and the source of publication.

Author Details: Peter Cunningham is an ecologist for the Zoological Society of London (ZSL) at the King Khalid Wildlife Research Centre at Thumamah, north of Riyadh in Saudi Arabia studying the feeding ecology of Sand Gazelle in protected areas as well as assisting with the management of the species.

Acknowledgements: My gratitude extends to H.H. Prince Bandar bin Saud bin Mohammed A Saud, Secretary General, NCWCD for his continued support towards conservation efforts in Saudi Arabia and Ernest Robinson (Director KKWRC) for his assistance in identifying many of the plant species and for commenting on a draft of this paper.
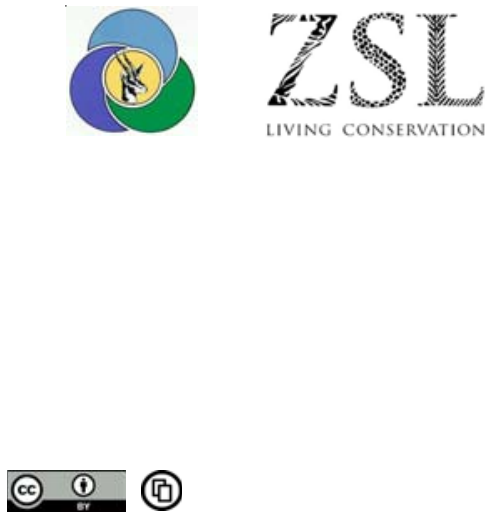

OPEN ACGESS | FREE DOWNLOAD
Abstract: Seasonal dietary preferences of male Arabian Sand Gazelle were determined using direct observations of vegetation utilised along foraging trails in central Saudi Arabia. Twentyone different plant species from 12 different families were identified as food items, of which six species have not previously been recorded in the diet from Saudi Arabia. The importance of forbs in the diet was confirmed with species selected throughout the year with the highest relative frequency of use including Farsetia stylosa, Convolvulus lanatus and Neurada procumbens. Knowledge of the diet and food preference is important for protected area managers.

Keywords: Diet, foraging trails, Gazella subgutturosa marica, reem, Saudi Arabia

\section{INTRODUCTION}

Herbivores in arid environments are frequently faced with problems of variable food quality and quantity which can be aggravated by overgrazing by livestock and wildlife (El Mouden et al. 2006). In general herbivores select a broader diet than would seem optimal and eat certain food types on some encounters but not on others (Owen-Smith 2008). It is thus crucial for species conservation to make sense of this and possess adequate data on feeding ecology. Little is known about the feeding ecology of Gazella subgutturosa marica Thomas, 1897 (reem/ rheem/ rim in Arabic) from Saudi Arabia (Habibi 1991) although some scientific work has been conducted on aspects such as genetics (Granjon et al. 1991; Vassart et al. 1993), ecophysiology (Williamson et al. 1991), population dynamics in captivity (Rietkerk et al. 1991) and daily activity and social organization (Launay \& Launay 1992).

G. s. marica are predominantly viewed as grazers, feeding on ephemeral plants after rains but generally relying on dry grasses, chenopods and desert melons (Thouless et al. 1991). Dwarf shrubs are important browse (Harrison \& Bates 1991), with Wacher (1995) indicating their use of bulbs, forbs, grasses and occasionally trees - i.e. browse in the Uruq bani M'arid Protected Area in southern Saudi Arabia. Haque (n.d.) confirms G. s. marica being grazers as observed in the Mahazat as-Sayd Protected Area in central western Saudi Arabia, with grazing preference shown towards Panicum and Stipagrostis grasses. Mowlavi (1978) noted that browsing formed the largest part of the diet (86\%) - increasing during the drier months - in Iran, while Mohamed \& Saleh (1991) state the importance of forbs in their diet from Bahrain.

Gazella subgutturosa Guldenstaedt 1780 ranges from western China through Mongolia, Afghanistan, Iran and south-eastern Turkey including the Arabian Peninsula (Harrison \& Bates 1991), with the subspecies G. s. marica confined to the Arabian Peninsula (Thouless et al. 1991) and the type locality documented as Nejd, central Arabia.

Gazella subgutturosa is classified as Vulnerable (A2ad: population size reduction over $30 \%$ over the last 10 years or three generations; a - direct observation; $\mathrm{d}$ - actual or potential levels of exploitation) by the IUCN (2008) with $35 \%$ of the global population share associated with Saudi Arabia (Dunham et al. 2001) and "endangered" by Flamand (1995). The subspecies marica is categorized as Vulnerable as the global population of Arabian Sand Gazelle is estimated to be less than 10,000 mature individuals with no subpopulation containing more than 1,000 mature individuals, and the largest subpopulation in Oman undergoing a continuing decline (Antelope Specialist Group 2008).

Although this study was limited to a single sex with a small sample size enclosed in a relatively small area without the entire range of potentially available vegetation (e.g. trees and larger shrubs), the aim of this paper is to quantify for the first time the diet of G. s. marica from central Saudi Arabia using back tracking as a technique. 


\section{Materials And Methods}

Two adult male G. s. marica kept under "natural" conditions in an enclosure of approximately 400ha in size were followed for one or two mornings each month from January 2008 to January 2009. The distance followed depended on the visibility of the tracks being followed, with a minimum of $5 \mathrm{~m}$ used arbitrarily and a mean of $458 \pm 38.2 \mathrm{~m}$ per month. Additional food - alfalfa - was supplied on a daily basis and the gazelle had free access to water. The gazelle were released into the pen in 2004 as part of a publicity/public relations exercise.

The technique used can be described as "back tracking". The area was crisscrossed until a fresh clearly visible foraging trail was intercepted. This foraging trail was then back tracked and all green plants within a $1 \mathrm{~m}$ width along the foraging trail (i.e. transect) were recorded and inspected for signs of feeding. This included clear bite damage to a plant, plant remains observed at a damaged plant and changes in the rhythm of the tracks followed indicating foraging (e.g. tracks closer together or local milling together with plant damage as clear evidence of foraging).

All the green - i.e. potentially palatable - plants along the transect were recorded and plants utilised - i.e. showing bite damage - were identified in situ or samples taken and identified with the use of the available literature (Collenette 1985) and the assistance of the King Khalid Wildlife Research Centre (KKWRC) resident botanist, Dr E.R. Robinson.

Absolute frequency of use was determined as the percentage of the food plant actually utilised in relation to the total amount of that specific plant. Relative frequency of use was determined as the percentage of the food plant actually utilised in relation to the total number of food plants potentially available. This method of analysis is based on that of Cavallini \& Serafini (1995).

A shortcoming of this study is that only two male gazelle were kept in the enclosure consequently limiting the statistical analysis and potentially indicating a bias in information only for males. However, as additional food (alfalfa) and water were supplied daily, the dietary selection could be viewed as true preference - i.e. food plant selection was not out of necessity as gazelle had access to alfalfa, but rather a true selection for plant species and plant parts.

\section{Study area}

The KKWRC is located approximately $70 \mathrm{~km}$ north of Riyadh in central eastern Saudi Arabia in an area known as Thumamah (Figure 1). The limestone Tuwaiq Escarpment borders the area towards the east with sandy-gravel plains and a belt of sand dunes towards the west $\left(25^{\circ} 13^{\prime} \mathrm{N} \& 46^{\circ} 37^{\prime} \mathrm{E}\right.$ elevation 600m) (Child \& Grainger 1990). The overall size of the general Thumamah protected area is $350 \mathrm{~km}^{2}$ (fenced) with the KKWRC fenced enclosure within this being approximately $20 \mathrm{~km}^{2}$. The fenced enclosure in which the feeding observations were made is approximately 400 ha in size. The pen originally housed a variety of wild ungulates with the last internal pens having been dismantled by 2007 and the vegetation having recovered naturally since the original occupants were removed. Thumamah falls within the phytogeographical region known as the Eastern Najd (Migahid 1978) or the floristic region known as the Saharo-Sindian (Guest 1966) or Sudanian (Mandaville 1984) and characterised by dwarf shrubland. The rainfall is highly variable and the average for several years is $107.8 \mathrm{~mm}$ per annum (Robinson 2008a). The vegetation in the study area is representative of the general area although having been severely degraded (overgrazed) due to the high densities of ungulates previously kept in the area, but since then having recovered with species previously locally scarce (although not viewed as rare) due to overgrazing having returned (E.R. Robinson pers. comm.). No other ungulates shared the study area although other mammals in the study area include a variety of small rodents, Ethiopian hedgehog (Paraechinus aethiopicus) and red fox (Vulpes vulpes).

\section{Results}

A total of 3,914 green (i.e. potential palatable) plants (spring-360, summer-1,161, autumn-247, winter-2,146) were encountered along the various foraging trails which extended over a total distance of $5,500 \mathrm{~m}$. These consisted of 32 plant species (6 grasses and 26 forbs) of which 21 species were utilised to some extent and 11 species (34.4\% - total; 2 grasses [33.3\%] \& 9 forbs [34.6\%]) avoided (not observed being utilized) throughout the year. The Gramineae utilised comprised four species and the forbs utilised comprised 11 families with Compositae having the most - i.e. three species - followed by Boraginaceae, Chenopodiaceae, Convolvulaceae and Cruciferae with two species each. All other families had one species each (Table 1).

During winter (92.3\%) and summer (67.4\%) forbs dominated the vegetation encountered along the foraging trails (Fig. 2). Forbs were more frequently utilised than grasses throughout the seasons (35.6\% versus $15.4 \%$ ).

Absolute frequency of use indicates the importance of the grass Stipagrostis plumosa, widespread in the area, throughout the year (Table 1). Furthermore grasses were utilised more often throughout the year except during summer and winter when the forbs Neurada procumbens $(46.7 \%)$ and Plantago boissieri $(67.7 \%)$ were utilised more often. The only grass to exceed a $50 \%$ relative frequency of use throughout the year was during spring when Panicum turgidium reached $65.5 \%$ ranking it the seventh most important food species. Panicum turgidium

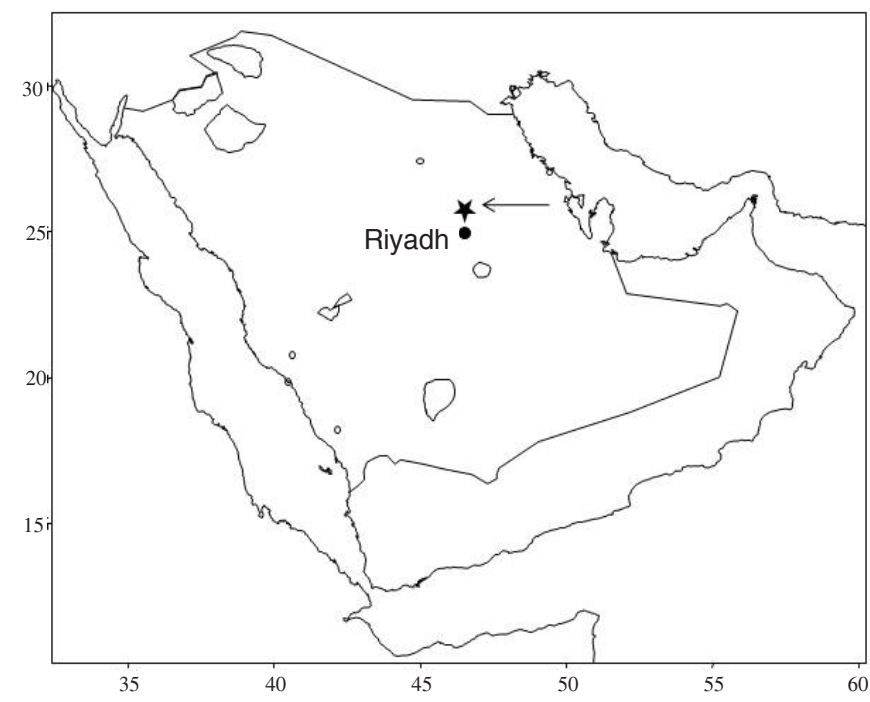

Figure 1. The study site at Thumamah indicated north of Riyadh in central Saudi Arabia. 
consistently had the highest relative frequency of use of the grasses (Table 1).

According to the relative frequency of use the importance of forbs is evident. Farsetia stylosa, Convolvulus lanatus and Neurada procumbens (ranked 1-3) were selected throughout the year and were consistently utilised above 60\% (Table 1). Neurada procumbens was also a dominant plant (high absolute frequency of use) associated with summer rainfall. Other seasonally important forbs with high relative frequency of use were Centuarea pseudosinaica (spring-80\%), Convolvulus oxyphyllus (summer - 68.2\%), Kochia indica (spring - 84.6\% \& summer $55.5 \%$ ) and Heliotropium rammosisima (winter $-41.9 \%$ ). Another forb utilized throughout the year albeit never at more than $50 \%$ relative frequency of use was Polycarpea repens.

\section{Discussion and Conclusion}

According to Owen-Smith \& Novellie (1982) foraging performance is more sensitive to changes in food quality than quantity, and a "clever ungulate" is defined as a short-term optimizer for performance alone. This study using foraging trails revealed that G. s. marica fed on a wide variety of plants (21 species in 12 families) of which six species (Cakile arabica, Centuarea pseudo sinaica, Kochia indica, Launaea cassiniana, Plantago boissieri \& Rumex vesicarius) have not previously been recorded in the diet from Saudi Arabia. The importance of forbs in the diet from central Saudi Arabia supports the findings of Mohamed \& Saleh (1991) from Bahrain. Important food plants (high relative frequency use) such as Farsetia stylosa and Convolvulus lanatus are ubiquitous although not dominant in the area. The nutrient content of the various plant species selected by G. s. marica during this study was not analysed although Farsetia sp. and Convolvulus lanatus are generally viewed as valuable fodder plants (Collenette 1985; Al-Zoghet 1989). It is interesting to note that Fabaceae were not observed to be

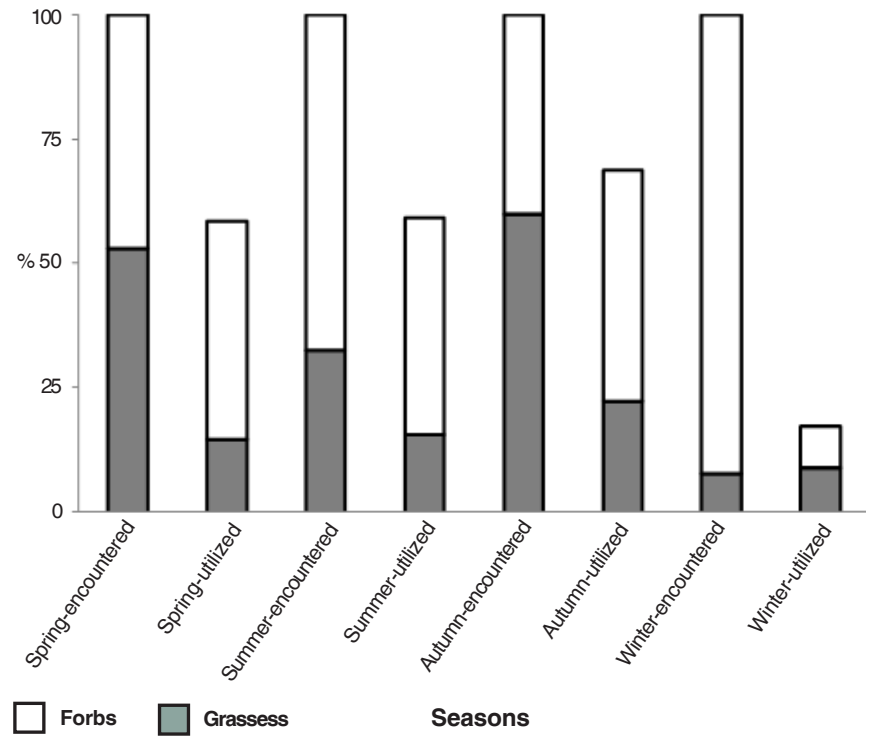

Figure 2. Seasonal differences in the forbs and grasses encountered and utilized by male Gazella subgutturosa marica $(\mathrm{N}=2)$ along foraging trails in central Saudi Arabia.

utilised although this is known to be an important family and often utilised by herbivores due to their high nutritional value (El Mouden et al. 2006). This is probably due to the absence of Acacia species in the enclosure as well as the typical legumes in the area being small and prostate forbs making it difficult to notice if utilisation has occurred.

Rainfall for 2008 was low with only $29.7 \mathrm{~mm}$ received during spring resulting in only 76 species of plants recorded for May 2008 although the average is 84.5 plant species thus indicating that the number of plant species is directly influenced by rainfall (Robinson 2008b). Vegetative response to rainfall, result in

Table 1. Relative and absolute frequency of food plants in the diet of male $(\mathrm{N}=2)$ Gazella subgutturosa marica along foraging trails in central Saudi Arabia. Species avoided are excluded. Three highest ranking species are indicated in bold.

\begin{tabular}{|c|c|c|c|c|c|c|c|c|c|c|c|c|}
\hline \multirow[b]{2}{*}{ Food item utilized } & \multicolumn{2}{|c|}{ Spring } & \multirow[b]{2}{*}{$\mathbf{N}$} & \multicolumn{2}{|c|}{ Summer } & \multirow[b]{2}{*}{$\mathbf{N}$} & \multicolumn{2}{|c|}{ Autumn } & \multirow[b]{2}{*}{$\mathbf{N}$} & \multicolumn{2}{|c|}{ Winter } & \multirow[b]{2}{*}{$\mathbf{N}$} \\
\hline & $\begin{array}{l}\text { Rel. } \\
\text { Fre. }\end{array}$ & $\begin{array}{l}\text { Abs. } \\
\text { Fre. }\end{array}$ & & $\begin{array}{l}\text { Rel. } \\
\text { Fre. }\end{array}$ & $\begin{array}{l}\text { Abs. } \\
\text { Fre. }\end{array}$ & & $\begin{array}{l}\text { Rel. } \\
\text { Fre. }\end{array}$ & $\begin{array}{l}\text { Abs. } \\
\text { Fre. }\end{array}$ & & $\begin{array}{l}\text { Rel. } \\
\text { Fre. }\end{array}$ & $\begin{array}{l}\text { Abs. } \\
\text { Fre. }\end{array}$ & \\
\hline \multicolumn{13}{|l|}{ Grasses } \\
\hline Lasiurus scindictus & & & & 100 & 0.09 & 1 & & & & & & \\
\hline Panicum turgidium & 65.5 & 8.1 & 29 & 41.4 & 2.5 & 29 & 20.4 & 21.9 & 54 & 18.5 & 1.3 & 27 \\
\hline Stipagrostis plumosa & 5.3 & 36.4 & 131 & 13.6 & 26.5 & 308 & 23 & 24.7 & 61 & 8.6 & 4.9 & 105 \\
\hline $\begin{array}{l}\text { Stipagrostis drarii } \\
\text { Forbs }\end{array}$ & 7.7 & 7.2 & 26 & 10.3 & 3.4 & 39 & 24.2 & 13.4 & 33 & 3.4 & 1.4 & 29 \\
\hline Cakile arabica & & & & & & & & & & 35.5 & 1.4 & 31 \\
\hline Centuarea pseudo sinaica & 80 & 1.4 & 5 & 100 & 0.09 & 1 & & & & 5.3 & 4.4 & 95 \\
\hline Convolvulus lanatus & 75 & 1.1 & 4 & 88.6 & 3 & 35 & 81.8 & 4.5 & 11 & 50 & 0.5 & 10 \\
\hline Convolvulus oxyphyllus & & & & 68.2 & 1.9 & 22 & & & & & & \\
\hline Fagonia brusweria & & & & 40 & 0.4 & 5 & & & & 33.3 & 0.3 & 6 \\
\hline Farsetia stylosa & 88.9 & 2.5 & 9 & 81.8 & 0.9 & 11 & 64.5 & 12.5 & 31 & 71.4 & 1.6 & 35 \\
\hline Haloxlylon salicornicum & 7.4 & 7.5 & 27 & & & & 6.5 & 12.5 & 31 & & & \\
\hline Heliotropium rammosisima & 25 & 1.9 & 8 & & & & & & & 41.9 & 1.4 & 31 \\
\hline Kochia indica & 84.6 & 3.6 & 13 & 55.5 & 0.9 & 11 & & & & 100 & 0.04 & 1 \\
\hline Launaea cassiniana & & & & & & & & & & 2.5 & 1.9 & 40 \\
\hline Moltchiopsis ciliata & 39.1 & 6.4 & 23 & 30.4 & 4.8 & 56 & & & & 25 & 0.8 & 16 \\
\hline Monsonea nivea & 70.4 & 7.5 & 27 & 33.3 & 0.3 & 3 & & & & 100 & 0.08 & 2 \\
\hline Neurada procumbens & 66.7 & 3.3 & 12 & 44.1 & 46.7 & 542 & 91.7 & 4.9 & 12 & 36.7 & 4.6 & 98 \\
\hline Plantago boissieri & 100 & 0.3 & 1 & 16.4 & 4.7 & 55 & & & & 3.2 & 67.7 & 1453 \\
\hline Polycarpea repens & 31.6 & 5.3 & 19 & 44.8 & 2.5 & 29 & 30.8 & 5.2 & 13 & 30.8 & 0.6 & 13 \\
\hline Rhanterium eppaposum & 100 & 0.3 & 1 & & & & & & & 14 & 2.3 & 50 \\
\hline Rumex vesicarius & & & & & & & & & & 100 & 0.08 & 2 \\
\hline Not eaten & & 7.2 & 25 & & 1.3 & 16 & & 0.4 & 1 & & 4.7 & 102 \\
\hline Total & & 100 & & & 100 & & & 100 & & & 100 & \\
\hline
\end{tabular}

Journal of Threatened Taxa | www.threatenedtaxa.org | September 2009 | 1(9): 445-449 


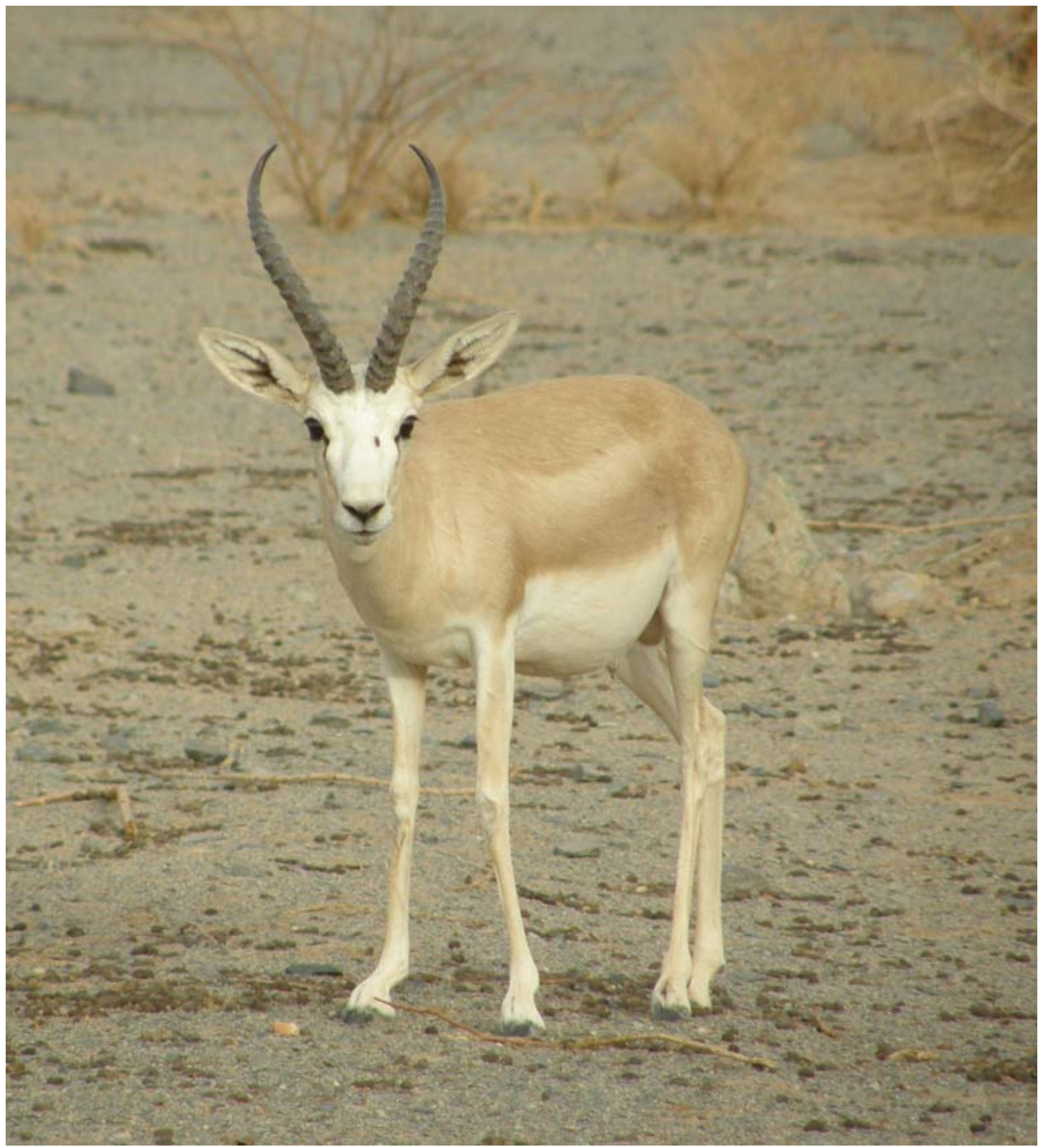

Image 1. A male Gazella subgutturosa marica from Saudi Arabia changes in plant selection as indicated by the increase in the use of Neurada procumbens during summer and autumn after the late spring rains and Plantago boissieri as a result of early winter rains. The diet and selection of plant and plant parts is thus affected by the intensity and seasonal distribution of rainfall indicating the importance to wildlife managers of monitoring rainfall events, intensity, distribution and related vegetative response.

Although G. s. marica feed on a wide variety of plants these species are also preferred by domestic stock indicating that where gazelle and domestic stock (e.g. goats \& camels) occur together in unfenced protected areas there is likely to be intense competition. This is especially important for Protected Areas in Saudi Arabia with a mainly gravel substrate as Gallacher \& Hill (2006) indicate that intense grazing by camels (which are viewed as major competitors of wild ungulates including gazelle in Saudi Arabia (Robertson 1993)) affect the plant ecology most on such substrate with heavy grazing furthermore reducing species richness and diversity and could affect the recruitment of perennial species (Gallacher \& Hill 2008). In future it would be useful to expand this study to include both sexes as well as different age classes of gazelle. Knowledge of the diet and plant preference of G. s. marica is useful for protected area managers and can assist with future envisaged reintroductions and be used as supportive argument to reduce the domestic stock grazing pressure in protected areas in Saudi Arabia.

\section{References}

Al-Zoghet, M. (1989). Wild plants of Jubail and Yanbu. Royal Commission for Jubail and Janbu, Riyadh, 195pp.

Cavallini, P. \& P. Serafini (1995). Winter Diet of the Small Indian Mongoose, Herpestes Auropunctatus, on an Adriatic Island. Journal of Mammology 76: 569-574.

Child, G. \& J. Grainger (1990). A System Plan for Protected Areas for Wildlife Conservation and Sustainable Rural development in Saudi Arabia - Appendix II. National Commission for Wildlife Conservation and Development, Riyadh, Saudi Arabia.

Collenette, S. (1985). An Illustrated Guide to the Flowers of Saudi Arabia. Scorpion Publishing LTD, London, 514pp.

Dunham, K.M., D.T. Williamson \& E. Joubert (2001). Saudi Arabia. In: Mallon, D.P. \& S.C. Kingswood (compilers). Antelopes Part 4: North Africa, the Middle East, and Asia. Global Survey and Action Plans. SSC Antelope Specialist Group. IUCN, Gland, Switserland and Cambridge, UK. pp. 55-62

El Mouden, E.H., T. Slimani, K. Ben Kaddour, F. Lagarde, A. Ouhammou \& X. Bonnet (2006). Testudo graeca graeca feeding ecology in an arid and overgrazed zone in Morocco. Journal of Arid Environments 64: 
$422-435$.

Flamand, J. (1995). Species status and a conservation strategy for Arabian sand gazelle or reem (Gazella subgutturosa marica) in Saudi Arabia. National Commission for Wildlife Conservation and Development, Riyadh, Saudi Arabia.

Gallacher, D.J. \& J.P. Hill (2006). Effects of camel grazing on the ecology of small perennial plants in the Dubai (UAE) inland desert. Journal of Arid Environments 66: 738-750.

Gallacher, D.J. \& J.P. Hill (2008). Effects of camel grazing on density and species diversity of seedling emergance in the Dubai (UAE) inland desert. Journal of Arid Environments 72: 853-860.

Granjon, L., M. Vassart, A. Greth \& E.P. Cribiu (1991). Genetic study of sand gazelles from Saudi Arabia. Zeitschrift fur Saugeterkunde 56: 169-176.

Guest, E. (1966). Flora of Iraq. Volume 1. Baghdad, Ministry of Agriculture, Iraq.

Habibi, K. (1991). Arabian Gazelles. NCWCD Publication No 4, Saudi Arabia, $131 \mathrm{pp}$.

Haque, M.N. (n.d.). Reintroducing Arabian sand gazelle at Mahazat asSayd. Unpublished report, National Commission for Wildlife Conservation and Development, Riyadh, $31 \mathrm{pp}$.

Harrison, D.L. \& P.J.J. Bates (1991). The Mammals of Arabia. Harrison Zoological Museum, England, 354pp.

IUCN (2008). The IUCN Red List of Threatened Species. IUCN, Gland, Switzerland.

IUCN SSC Antelope Specialist Group (2008). Gazella subgutturosa ssp. marica. In: IUCN 2009. IUCN Red List of Threatened Species. Version 2009.1. <www.iucnredlist.org>. Downloaded on 29 August 2009.

Launay, F. \& C. Launay (1992). Daily activity and social organization of the Goitered Gazelle (Gazella subgutturosa marica). Ungulates 91: 373-377.

Mandaville, J.P. (1984). Studies in the flora of Arabia XI. Some historical and geographical aspects of a principal floristic frontier. Notes from the Royal Botanic Garden Edinburgh 42(1): 1-15.

Migahid, A.M. (1978). Flora of Saudi Arabia. Riyadh University Publication, Riyadh, Saudi Arabia, 647pp.

Mohamed, S.A. \& M. Saleh (1991). Natural diet of the Arabian Rheem, Gazella subgutturosa marica. Journal of Arid Environments 20: 371-374.
Mowlavi, M. (1978). Ecological studies of the goitered gazelle (Gazella subgutturosa) in Khosh Yeilagh refuge, Iran. MSc Thesis, Michigan State University.

Owen-Smith, N. \& P. Novellie (1982). What should a clever ungulate eat? The American Naturalist 119(2): 151-178.

Owen-Smith, N. (2008). Effects of temporal variability in resources on foraging behaviour, pp. 159-181. In: Prins, H.H.T. \& F van Langevelde (eds.). Resource Ecology: Spatial and Temporal Dynamics of Foraging. Springer, 303pp.

Rietkerk, F.E., N. Lindsay, H. Tatwany, S. Mubarak, O. Badri \& D.T. Williamson (1991). Population dynamics of a captive herd of Arabian sand gazelles. Ungulates 91: 379-382.

Robertson, F. (1993). Camel densities in the special Ibex Reserve at Hawtah Bani Tamim. Unpublished Report, King Khalid Wildlife Research Centre, Thumamah, Saudi Arabia, 18pp.

Robinson, E.R. (2008a). Thumamah weather. Annual Report, King Khalid Wildlife Research Centre, Thumamah, Saudi Arabia, 217pp.

Robinson, E.R. (2008b). Thumamah vegetation monitoring, weather and climate change. $2^{\text {nd }}$ Quarterly Report 2008. King Khalid Wildlife Research Centre, Thumamah, Saudi Arabia, 42pp.

Thouless, C.R., J.G. Grainger, M. Shobrak \& K. Habibi (1991). Conservation status of gazelles in Saudi Arabia. Biological Conservation 58: 85-98.

Vassart, M., A. Greth, V. Durand \& E.P. Cribiu (1993). Chromosomal polymorphism in sand gazelles (Gazella subgutturosa marica). The Journal of Heredity 84(6): 478-481.

Wacher, T. (1995). Sand gazelle monitoring at Uruq Bani Ma'Arid. $3^{\text {rd }}$ Progress Report. King Khalid Wildlife Research Centre, Thumamah, Saudi Arabia, 15pp.

Williamson, D.T., H. Tatwany, F.E. Rietkerk, E. Delima \& N. Lindsay (1991). Temperature lability in the Arabian sand gazelle. Ungulates 91. 